\title{
Effect of sol-gel solution parameters on the formation of films on the surface of carbon fibers
}

\author{
Rida Gallyamova ${ }^{1, *}$, Rustam Safiullin ${ }^{1}$, Vladimir Dokichev $^{1}$, and Fanil Musin ${ }^{1}$ \\ ${ }^{1}$ Ufa Institute of Chemistry UFRS RAS, 450054, Ufa, Russia
}

\begin{abstract}
In this study to apply an oxide film to the surface of carbon fibers a sol-gel solution was used. Sol-gel solutions were prepared according to the described procedure from tetraethoxysilane (TEOS) and ethanol at various $\mathrm{H} 2 \mathrm{O}$ concentrations. The molar ratio $\mathrm{H} 2 \mathrm{O} / \mathrm{TEOS}$ ratio was changed in the range from 2 to 20. After coating and drying, the surface morphology of carbon fibers was investigated. The relationship between the concentration of sol-gel solutions and the amount of deposited $\mathrm{SiO} 2$ on the surface of carbon fibers was analyzed.
\end{abstract}

\section{Introduction}

In recent years, the sol-gel method has been one of the most promising methods for producing oxide films. Using the sol-gel method, it is possible to obtain thin ceramic films not only on various kinds of fibers, but also on any surfaces of various materials $[1,2]$.

It is of interest to use ceramic films as diffusion barriers in metal matrix composite materials to prevent chemical interaction at the fiber/matrix interface, such as carbon/aluminum alloy $[3,4]$. Due to their high chemical resistance, oxide films should improve the wettability of the carbon fiber and matrix, and prevent the formation of carbides, which adversely affects the properties of the entire composite.

The properties of the films primarily depend on the physicochemical characteristics of the sol-gel solution. To obtain films uniform in composition, the sol-gel solution must contain a certain ratio of the initial film-forming substance, solvent, and catalyst. Recent works [5-9] showed that hydrolysis and polycondensation processes are accompanied by a change in the viscosity of the sol-gel solution, which is an important criterion for the formation of uniform films on the fiber surface. In [8], the study of the sol-gel solution viscosity from its lifetime was performed and some regularities of the formation of films when they are applied to the surface of carbon fibers were determined.

At the same time, one of the main factors affecting the sol-gel process is the concentration of water in the solution. In $[10,11]$, it was found that sols with a low water concentration contribute to the formation of a linear structure - long chains of macromolecules, which are interconnected by Van der Waals forces, which is preferable for producing oxide fibers. At a high concentration of water in the sol, a three-dimensional

\footnotetext{
* Corresponding author: rida_gallyamova@mail.ru
} 
structure of colloidal particles is formed, which is preferable for producing glasses. It is important to note that the ratio of the components in the sol-gel solution should, on the one hand, provide hydrolysis and condensation while preserving the resulting hydrolysis products in the form of a sol, and, on the other hand, the final hydrolysis in a thin layer of the obtained product when are applied an oxide film to the surface of carbon fibers.

In this work, we studied the effect of water concentration on the properties of a sol-gel solution and the formation of $\mathrm{SiO}_{2}$ film on the surface of carbon fibers.

\section{Materials and method}

A solution of tetraethoxysilane (TEOS) in ethanol as a source of silicon dioxide was used. The sol-gel solution was prepared according to the following procedure: a mixture of TEOS and ethanol solutions in a ratio of 1: 0.5 was intensively mixed for 30 minutes. A solution containing water and ethanol (another part) acidified with a $1 \mathrm{M} \mathrm{HCl}$ solution was slowly added dropwise to the first mixture. The resulting solution was stirred for 30 minutes. In this study, various sols with a molar ratio of $\mathrm{H}_{2} \mathrm{O}$ /TEOS (MR) in the range from 2 to 20 were used (table 1).

Table 1. The composition of the sol-gel solution at various concentrations of water.

\begin{tabular}{|c|c|c|c|c|}
\hline MR & TEOS, $\mathrm{ml}$ & $\mathrm{EtOH}, \mathrm{ml}$ & $\mathrm{H}_{2} \mathrm{O}, \mathrm{ml}$ & $\mathrm{HCl}, \mathrm{ml}$ \\
\hline 2 & \multirow{6}{*}{22} & \multirow{6}{*}{23,3} & 3.6 & \multirow{6}{*}{0.13} \\
\hline 4 & & & 7.2 & \\
\hline 6 & & & 10.8 & \\
\hline 8 & & & 14.4 & \\
\hline 10 & & & 18.0 & \\
\hline 20 & & & 36.1 & \\
\hline
\end{tabular}

The kinematic viscosity of the sol-gel solution was evaluated at room temperature using a capillary viscometer. The calculation was carried out according to the following formula:

$$
v=\frac{g}{9,807} \cdot \tau \cdot K
$$

where $v$ is the kinematic viscosity of the solution, $\mathrm{mm}^{2} / \mathrm{s} ; \mathrm{K}=0.01060 \mathrm{~mm}^{2} / \mathrm{s}^{2}$, viscometer constant; $\tau$ is the time of expiration of the solution through the capillary, $\mathrm{s} ; \mathrm{g}$ acceleration of gravity at the measurement site in $\mathrm{m} / \mathrm{s}^{2}$.

In order to determine the amount of $\mathrm{SiO}_{2}$ formed at different molar ratios of $\mathrm{H}_{2} \mathrm{O}$ /TEOS, films were deposited on the surface of carbon fibers. In this study, carbon fibers from a PAN precursor of the brand UMT49-12K-EP (Russia) were used; the average diameter of one filament is $5.5 \mu \mathrm{m}$. Carbon fibers were preliminarily subjected to heat treatment at a temperature of $400{ }^{\circ} \mathrm{C}$ for 20 minutes to remove polymer size from the surface [12]. Carbon fibers were immersed in the obtained sol-gel solution and held for 15 seconds. Then, the coated fibers were dried in air for 30 minutes and then subjected to heat treatment at a temperature of $500{ }^{\circ} \mathrm{C}$ (the heating rate to a given temperature was $2.5{ }^{\circ} \mathrm{C} / \mathrm{min}$ ). The amount of precipitated $\mathrm{SiO}_{2}$ was determined by burning carbon fibers and measuring the oxide residue. The surface morphology of carbon fibers was studied using a scanning electron microscope (JEOL, Japan). 


\section{Results and discussion}

\subsection{Effect of water concentration on the viscosity of the sol-gel solutions}

The effect of water concentration on the processes occurring in the sol-gel solution was evaluated by measuring the kinematic viscosity of the resulting solutions. Dependence of the kinematic viscosity at various molar ratios of $\mathrm{H}_{2} \mathrm{O}$ /TEOS is shown in fig. 1 . An increase in water concentration leads to an increase in the viscosity values of the sol-gel solution. This is primarily due to the fact that an increase in water concentration accelerates hydrolysis processes. At the same time, a slight decrease in viscosity is observed above $\mathrm{MR}=8\left(\right.$ at $\left.\mathrm{MR}=10-3.6 \mathrm{~mm}^{2} / \mathrm{s}\right)$ and a further increase in MR does not lead to sharp changes in viscosity. At low values of water $(M R=2)$, partial hydrolysis of TEOS takes place, which suggests a low concentration of particles and the corresponding low viscosity values. An increase in viscosity with increasing water concentration indicates an acceleration of gelation processes. Previous kinematic viscosity studies [8] showed that the sol is in a stable state in the range of viscosity values of $3.6-3.7 \mathrm{~mm}^{2} / \mathrm{s}$ and is preferred for applying films to the surface of carbon fibers.

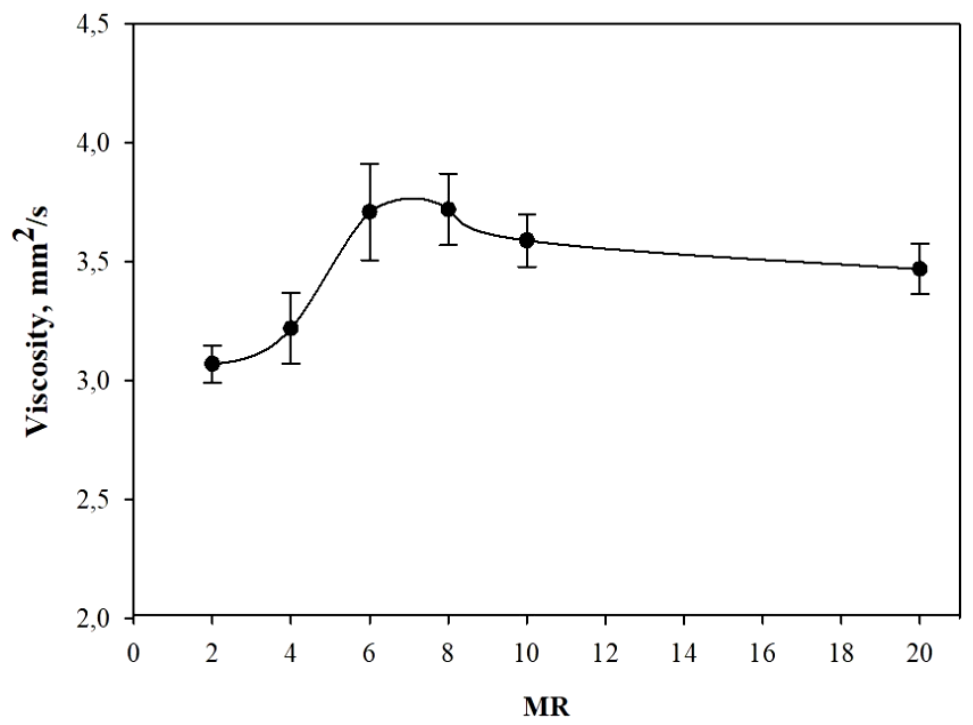

Fig. 1. Change in kinematic viscosity at various concentrations of water.

Thus, the use of low concentrations of water (MR below 6) in the sol-gel solution during film deposition leads to an excess of TEOS in the solution and, consequently, to the appearance of cracks during the drying of the film. A higher concentration of water in the solution, with MR values above 6 , contributes to the formation of crack-free $\mathrm{SiO}_{2}$ films on the surface of the carbon fiber.

\subsection{Effect of water concentration on the formation of $\mathrm{SiO}_{2}$ films}

To estimate the amount of $\mathrm{SiO}_{2}$ formed at different molar $\mathrm{H}_{2} \mathrm{O}$ /TEOS ratios were deposited film on the surface of carbon fibers. The surface of carbon fibers with a deposited $\mathrm{SiO}_{2}$ film is shown in Fig. 2. In the initial state, the surface of the fiber subtle longitudinal bands are observed Ffig. 2 a). After deposition of the oxide film, electron microscopy studies showed that at $\mathrm{MR}=6$ (Fig. 2 b) and above, the $\mathrm{SiO}_{2}$ film is applied uniformly on the surface of 
carbon fibers (the arrows indicate the $\mathrm{SiO}_{2}$ film boundary). This is due to the fact that high concentrations of water contribute to the complete hydrolysis in the sol-gel solution, which does not complicate the deposition of $\mathrm{SiO}_{2}$ on the fiber surface.

Low water concentrations (at $\mathrm{MR}=2$ and $\mathrm{MR}=4$ ) $\mathrm{SiO}_{2}$ film is cracked and peeled off. This is due to the fact that low concentrations of water slow down the hydrolysis processes, that is, i.e. it extends partially. In turn, partial hydrolysis indicates an excess of TEOS, which evaporates during the heat treatment and leads to cracking in the oxide film. This is the reason for the smaller amount of deposited silicon dioxide on the surface of carbon fibers (Fig. 3).
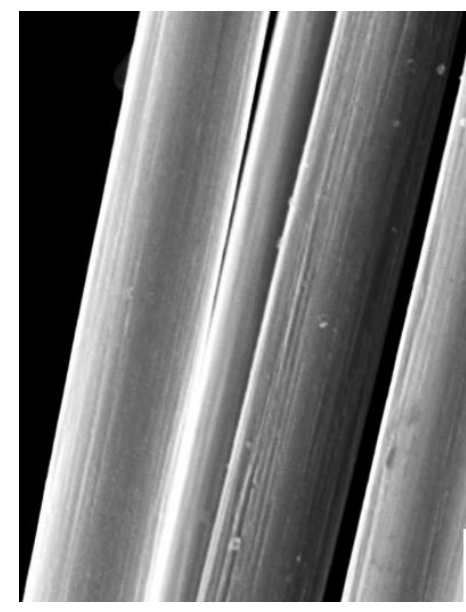

a
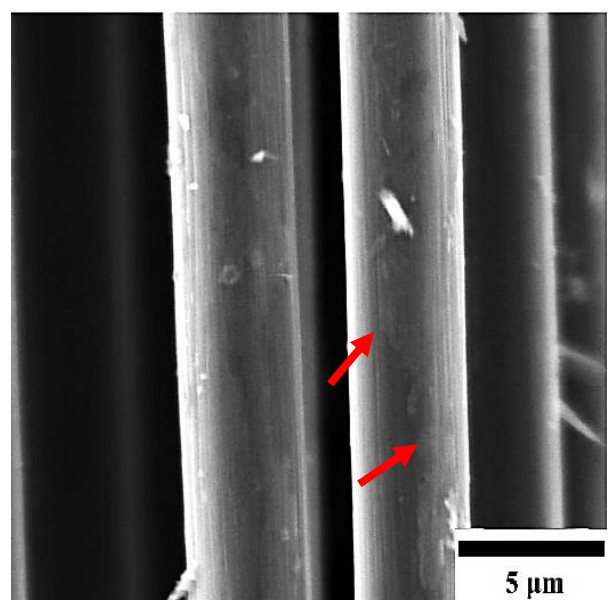

b

Fig. 2. The surface of carbon fibers: a) the initial fiber without $\mathrm{SiO}_{2}$ film; b) with a $\mathrm{SiO}_{2}$ film at $\mathrm{MR}=6$ (arrows indicate the boundary of the oxide film).

Dependence of the mass of deposited $\mathrm{SiO}_{2}$ on the surface of the fibers at various concentrations of water is shown in fig. 3. Analyzing the obtained dependence, one can see that at $\mathrm{MR}=2$ and $\mathrm{MR}=4$, the amount of silicon oxide is lower than at $\mathrm{MR}=6$. The largest amount of silicon oxide is deposited at $\mathrm{MR}=6(17 \%)$, which corresponds to an increase in viscosity. A further increase in water concentration leads to a decrease in the amount of $\mathrm{SiO}_{2}$.

At low water concentrations, as described above, the hydrolysis rate decreases, which contributes to the formation of a weakly branched structure corresponding to low values of the deposited $\mathrm{SiO}_{2}$ mass and viscosity. High concentrations of water slow down the polycondensation processes, which indicate a decrease in the amount of $\mathrm{SiO}_{2}$ and a slight decrease in the viscosity of sol-gel solutions. Thus, at high concentrations of water (MR above 6 ), the formation of an oxide film on the surface of carbon fibers occurs uniformly. 


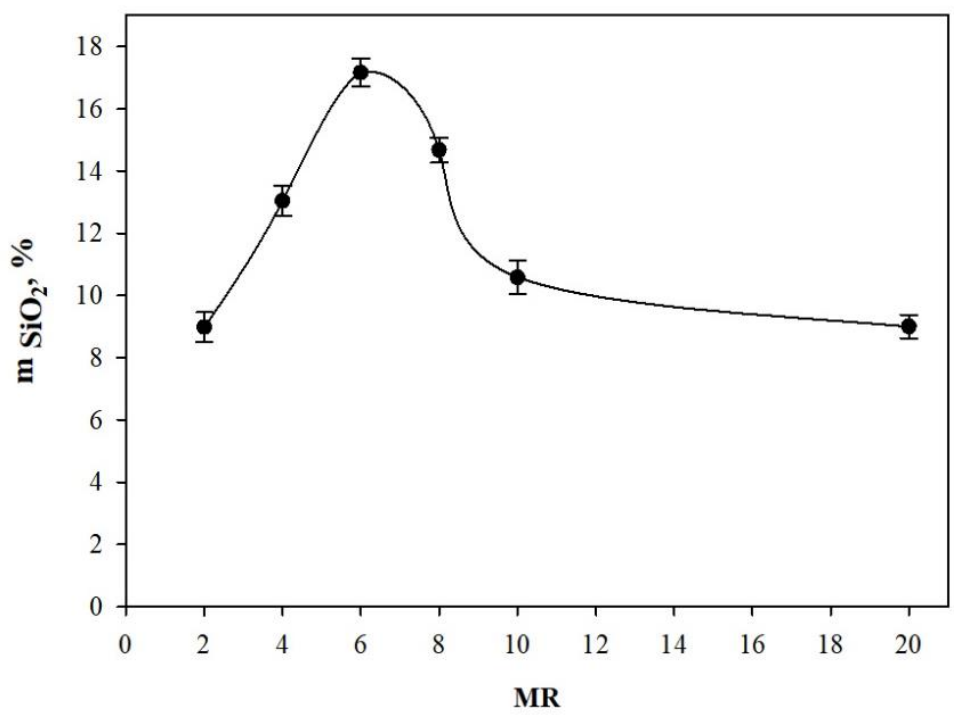

Fig. 3. The amount of deposited silicon oxide on the surface of carbon fibers, depending on the molar ratio of $\mathrm{H}_{2} \mathrm{O} / \mathrm{TEOS}$.

\section{Conclusion}

The results of the studies showed that the concentration of water significantly affects the formation of $\mathrm{SiO}_{2}$ films on the surface of carbon fibers:

- low water concentrations (MR <6) lead to a slowdown in hydrolysis and an excess of TEOS, a decrease in the viscosity of the obtained sol-gel solutions and, accordingly, form cracks in the $\mathrm{SiO}_{2}$ film;

- at high water concentrations $M R \geq 6$, the viscosity of the sol-gel solutions does not change significantly and the formation of the $\mathrm{SiO}_{2}$ film occurs uniformly.

Thus, the optimal molar ratio $\mathrm{H}_{2} \mathrm{O}$ /TEOS at which $\mathrm{SiO}_{2}$ films are formed without visible defects on the fiber surface is in the range from 6 to 20 .

This work was performed on the subject № AAAA-A17-1170011910021-8 of the state assignment of the Ufa Institute of Chemistry Russian Academy of Sciences and with the financial support of the grant to young scientists of the Republic of Bashkortostan (No. 5GR/2020).

\section{References}

1. T. Wen, J. Gao, J. Shen, Z. Zhou, J. Mater. Sci. 36, (2001)

2. R.F. Gallyamova, S.N. Galyshev, F.F. Musin, A.G. Badamshin, V.A. Dokichev, Solid state phenomena, 284 (2018)

3. T. Rajan, R. Pillai, B. Pai, J. Mater. Sci. 33, 3491 (1998)

4. C. R. Durkin, Dissertation, Georgia Institute of Technology, (2007)

5. V.V. Kozik, L.P. Borilo, A.G. Malchik, Journal of Applied Chemistry, 69, (1996)

6. L.N. Novoselova, Journal of Applied Chemistry, 8, (1982)

7. I. Strawbridge, P.F. James, Journal of Non-Crystalline Solids, 86, (1986) 
8. R. Gallyamova, S. Galyshev, F. Musin, V. Dokichev, MATEC Web of Conferences, 298, (2019)

9. E.N. Poddenezhnyy, A.A. Boyko, A.A. Alekseyenko, Vestnik GGTU, 4, (2003)

10. S. Sakka, Formation of Glass and Amorphous Oxide Fibers from Solution (Elsevier Science Publishing, New York, 1984)

11. H. Tototzintle-Huitle, Journal of materials science, 37, (2002)

12. M.I. Valuyeva, I.V. Zelenina, M.A. Khaskov, A.I. Gulyayev, Trudy VIAM, 10, 2017 